\begin{tabular}{|c|c|}
\hline Title & $\begin{array}{l}\text { Wet/Dry Cycle Corrosion Behavior of Model Cut-Edge Formed on Pre Painted Zinc A lloy Coated Steels by Laser } \\
\text { Fabrication }\end{array}$ \\
\hline Author(s) & Sakairi, Masatoshi; Kageyama, A kihiro; Kikuchi, Tatsuya \\
\hline Citation & $\begin{array}{l}\text { ECS Transactions, } 25(29), 71-79 \\
\text { https://doi.org/10.1149/1.3327226 }\end{array}$ \\
\hline Issue Date & 2010 \\
\hline Doc URL & http:/hdl.handle.net/2115/50145 \\
\hline Rights & $\begin{array}{l}\text { (1) The Electrochemical Society, Inc. 2010. All rights reserved. Except as provided under U.S. copyright law, this work } \\
\text { may not be reproduced, resold, distributed, or modified without the express permission of The Electrochemical Society } \\
\text { (ECS). The archival version of this work was published in ECS Trans. 2010 volume 25, issue 29, } 71-79 \text {. }\end{array}$ \\
\hline Type & article \\
\hline File Information & ECSt25-29_71-79.pdf \\
\hline
\end{tabular}

Instructions for use 


\section{Wet/Dry Cycle Corrosion Behavior of Model Cut-Edge Formed on Pre-Painted Zinc Alloy Coated Steels by Laser Fabrication}

Masatoshi Sakairi, Akihiro Kageyama and Tatsuya Kikuchi

ECS Trans. 2010, Volume 25, Issue 29, Pages 71-79.

doi: 10.1149/1.3327226

Email alerting Receive free email alerts when new articles cite this article - sign up in the service box at the top right corner of the article or click here 


\title{
Wet/Dry Cycle Corrosion Behavior of Model Cut-Edge Formed on Pre-painted Zinc Alloy Coated Steels by Laser Fabrication
}

\author{
M. Sakairi, A. Kageyama and T. Kikuchi \\ Graduate School of Engineering, Hokkaido University, Sapporo, 060-8628. Japan \\ Laser machining technique, which used focusing pulse YAG laser \\ beam irradiation, was applied to form area ratio of controlled \\ model cut-edge on pre-painted zinc related coated steels. A \\ corrosion behavior of formed model cut-edge was investigated by \\ wet/dry cyclic corrosion test using $10 \mathrm{~mol} \mathrm{~m}^{-3} \mathrm{NaCl}$ solutions in \\ $80 \%$ R.H. atmosphere. In high area ratio zinc specimens, red rust \\ is observed on steel substrate at model cut-edge. The chromate \\ inhibits corrosion of formed model cut-edge on pre-painted zinc \\ coated steels. The behavior of corrosion penetration under the paint \\ depends on composition of coating. In the case of painted zinc-55 \\ mass $\%$ aluminum coated steel, zinc rich phase preferentially \\ dissolved. The preferential zinc rich layer dissolution and \\ corrosion products formation cause paint peel off.
}

\section{Introduction}

Zinc or zinc alloy coated steels are widely used because of their high corrosion resistance in many corrosive environments. Therefore many books and papers related to corrosion of the coated steels were published (1- 9). In Japan, many electrical goods, such as washing machine, refrigerator and so on, use pre-painted coated steels. In general, no further coating process is carried out at the cut edge face, which was formed while machining to fabricate. Therefore, one of the weak regions of the pre-coated steels for corrosion is the cut-edge face. Especially, outdoor unit of air-conditioner is exposed to very severe corrosion environment and sometimes corrosion problems occur at the cutedge.

Until now, $\mathrm{Cr}^{6+}$ ions related surface treatment and presence of $\mathrm{Cr}^{6+}$ related chemicals in paint reduce the corrosion rate of metals at cut-edge in many corrosive environments. Because $\mathrm{Cr}^{6+}$ ion is a highly hazardous substance, the hazardous substances are prohibited from using for industrial products by some standard, such as RoHS and ELV. The recent situation becomes more severe for cut-edge corrosion of pre-painted coated steels. Therefore, many researchers in Japan have studied the cut-edge corrosion using a model cut-edge, which is formed by machining (10). The machining technique can form model cut-edge quickly and easily, however, machining technique has disadvantages, such as formation of burrs and difficult to control exposed area ratio of coating and steel substrate, $\mathrm{S}_{\mathrm{r}}$. Fig 1 shows schematic drawing for formation of model cut-edge by mechanical cutting.

To avoid burr and difference of $\mathrm{S}_{\text {ratio }}$ between each sample, the laser fabrication technique was investigated, using focused pulse YAG laser beam irradiation. It has been reported that fabrication of a three-dimensional micro-manipulator and micro-reactor by laser irradiation and electrochemical techniques (11-13). This technique allows us to form 

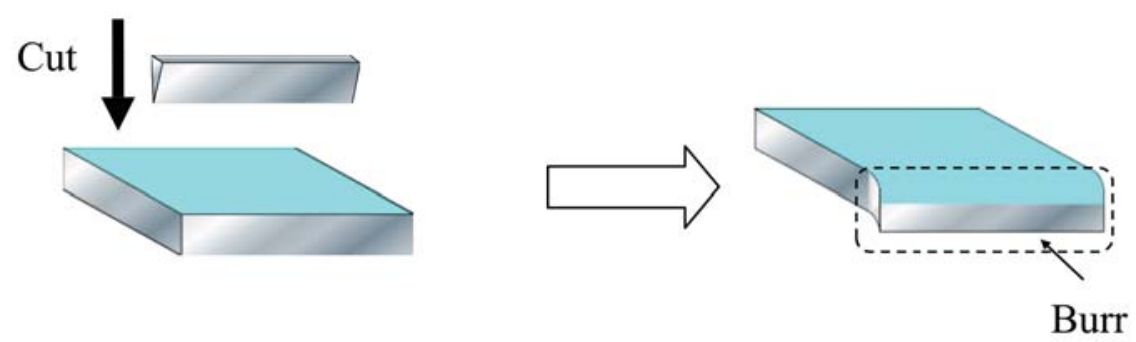

Figure. 1 Schematic drawing for fabrication of model cut-edge by cutting.

burr free edges and control $\mathrm{S}_{\mathrm{r}}$. Model cut-edge corrosion behavior has been investigated by immersion potential measurement. The rest potential showed almost constant value with fluctuations and the amplitude of fluctuations increased with exposed area of steel surface (14). White corrosion products of zinc oxide and simonkollite were formed after the experiments at the formed model cut-edge.

The purpose of this study is to investigate effect of $\mathrm{S}_{\mathrm{r}}$ on corrosion behavior of model cut-edge formed pre painted zinc and zinc 55 mass $\%$ aluminum coated steels by wet/dry cyclic corrosion test.

\section{Experimental}

\section{Specimen}

Four different pre-painted coated steel sheets, zinc coated with chromate free and chromate painting ( $\mathrm{Zn}-\mathrm{CF}, \mathrm{Zn}-\mathrm{CR}$ respectively), and zinc 55 mass\% aluminum coated with chromate free and chromate containing painting (GL-CF, GL-CR respectively) were studied. The size of the sheets was $15 \times 20 \mathrm{~mm}$. Before the experiments, specimens were cleaned in doubly distilled water and an ethanol ultrasonic bath. To form model cut edge, specimens were irradiated by a focused Nd-YAG laser beam (Sepctra Physics GCR-130, wave duration $8 \mathrm{~ns}$, frequency $10 \mathrm{~s}^{-1}$, wave length $532 \mathrm{~nm}$ ) in $0.5 \mathrm{kmol} \mathrm{m}^{-3} \mathrm{H}_{3} \mathrm{BO}_{3} / 0.05$ $\mathrm{kmol} \mathrm{m}^{-3} \mathrm{Na}_{2} \mathrm{~B}_{4} \mathrm{O}_{7}$ solutions, while laser beam irradiation, specimens were moved by $\mathrm{X}$ Y stage to control $S_{r}=0.7$ to 6.0 . The laser beam power was adjusted to $20 \mathrm{~mW}$ in front of the lens. Fig. 2 shows schematic drawing of formation of model cut-edge by laser irradiation.

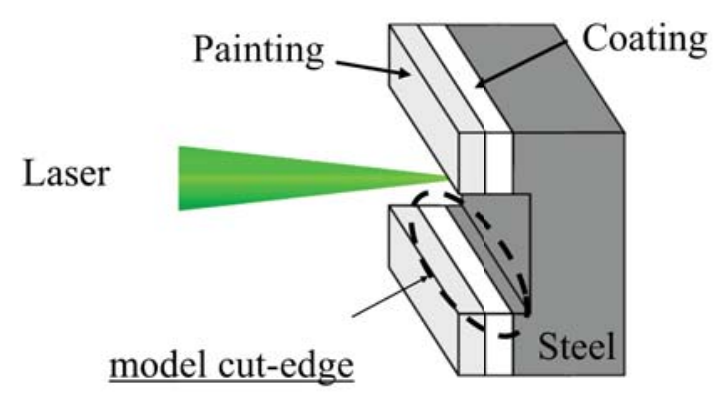

Figure 2. Schematic drawing of formation of model cut-edge by laser irradiation. 


\section{$\underline{\text { Wet/dry Corrosion test }}$}

After formation of model cut-edge, electrolyte droplet, which volume is $10 \mu \mathrm{L}$ and concentration is $10 \mathrm{molm}^{-3} \mathrm{NaCl}$ was put on the cut-edge by micro-pipet. Then specimens were kept in $80 \%$ R.H. vessel for 84 ks. The R.H. in the vessel was controlled by saturated $\mathrm{NaCl}$ solution. After $84 \mathrm{ks}$, specimens were washed by doubly distilled water to avoid accumulation of $\mathrm{NaCl}$. These consecutive processes are as one cycle, and several cycles were carried out. After the experiments, specimen surfaces were examined by optical microscope and scanning electron microscope.

\section{Results and discussion}

\section{Corrosion behavior of $\mathrm{Zn}-\mathrm{CR}$ and $\mathrm{Zn}-\mathrm{CF}$}

Figure 3 shows optical images of $\mathrm{Zn}-\mathrm{CR}$ specimens, $\mathrm{S}_{\mathrm{r}}=0.7$ and 6.0 , after 7 cycles of wet/dry corrosion test. There are zinc oxide related white corrosion products at formed model cut-edge. The corrosion products showed very good adhesiveness. In the case of $\mathrm{S}_{\mathrm{r}}$ less than 1.4, the cut-edge was totally covered by corrosion products. In the case of $\mathrm{S}_{\mathrm{r}}$ is lager than 3, corrosion products only covered at outer area of the model cut-edge. A red rust is observed at center area of $\mathrm{S}_{\mathrm{r}}=6.0$ specimen surface, where white corrosion products are not covered. The white corrosion products formed on zinc coating may be simonkollite and zinc oxide (15). This result indicates that the white corrosion products are very compact and have corrosion inhibition property. In the case of only around the model cut-edge area was covered by compact corrosion products, sacrificial reaction of zinc coating is no longer active or further zinc coating corrosion is inhibited. In this situation, the exposed steel substrate corrodes to form red rust.

(a) $\mathrm{S}_{\mathrm{r}}=0.7$

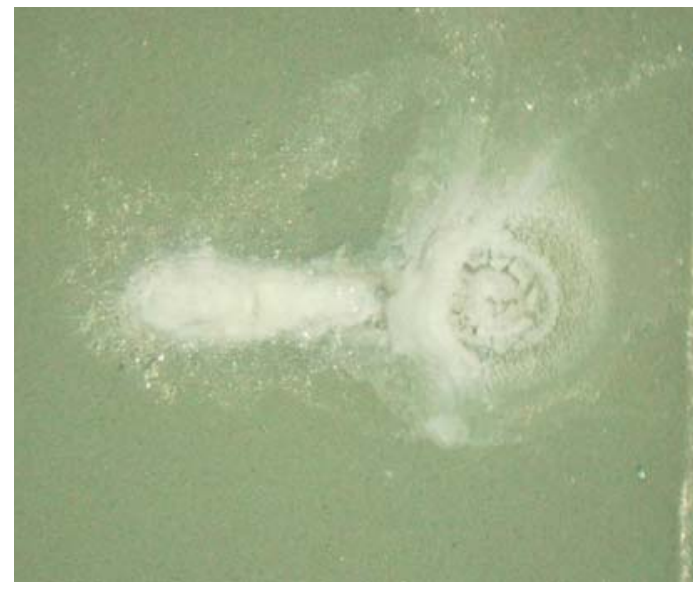

(b) $\mathrm{S}_{\mathrm{r}}=6.0$

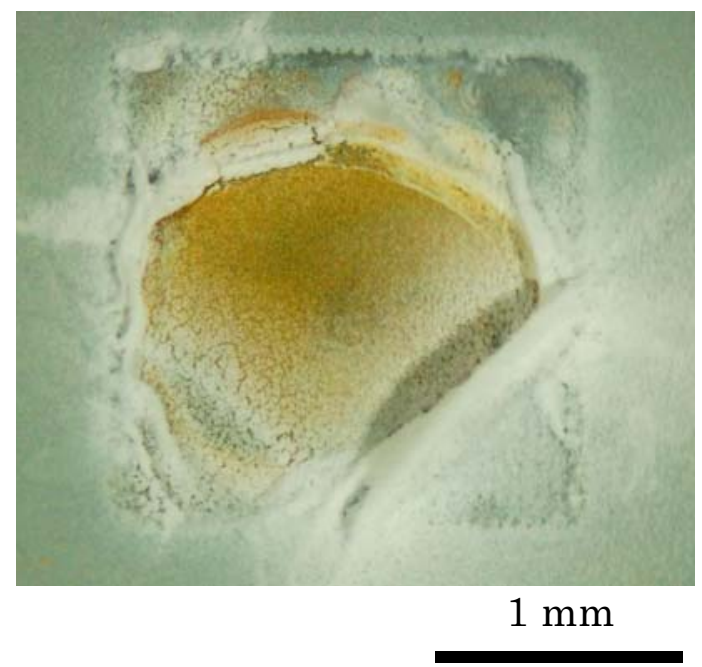

Figure 3. Optical images of Zn-CR after 7 cycles of wet/dry corrosion test.

Figure 4 shows SEM images of cross-section of Zn-CR after wet-dry cycle corrosion test, $S_{r}=$ (a) 0.70 , (b) 6.0. Left row is magnified images, and right row is overall images. The center dent area may be formed during laser fabrication, because, used laser beam energy has Gaussian distribution. Formed model cut-edge of $\mathrm{S}_{\mathrm{r}}=0.7$ specimen is completely covered by corrosion products, while that of $S_{r}=6.0 \mathrm{~s}$ specimen is partially 

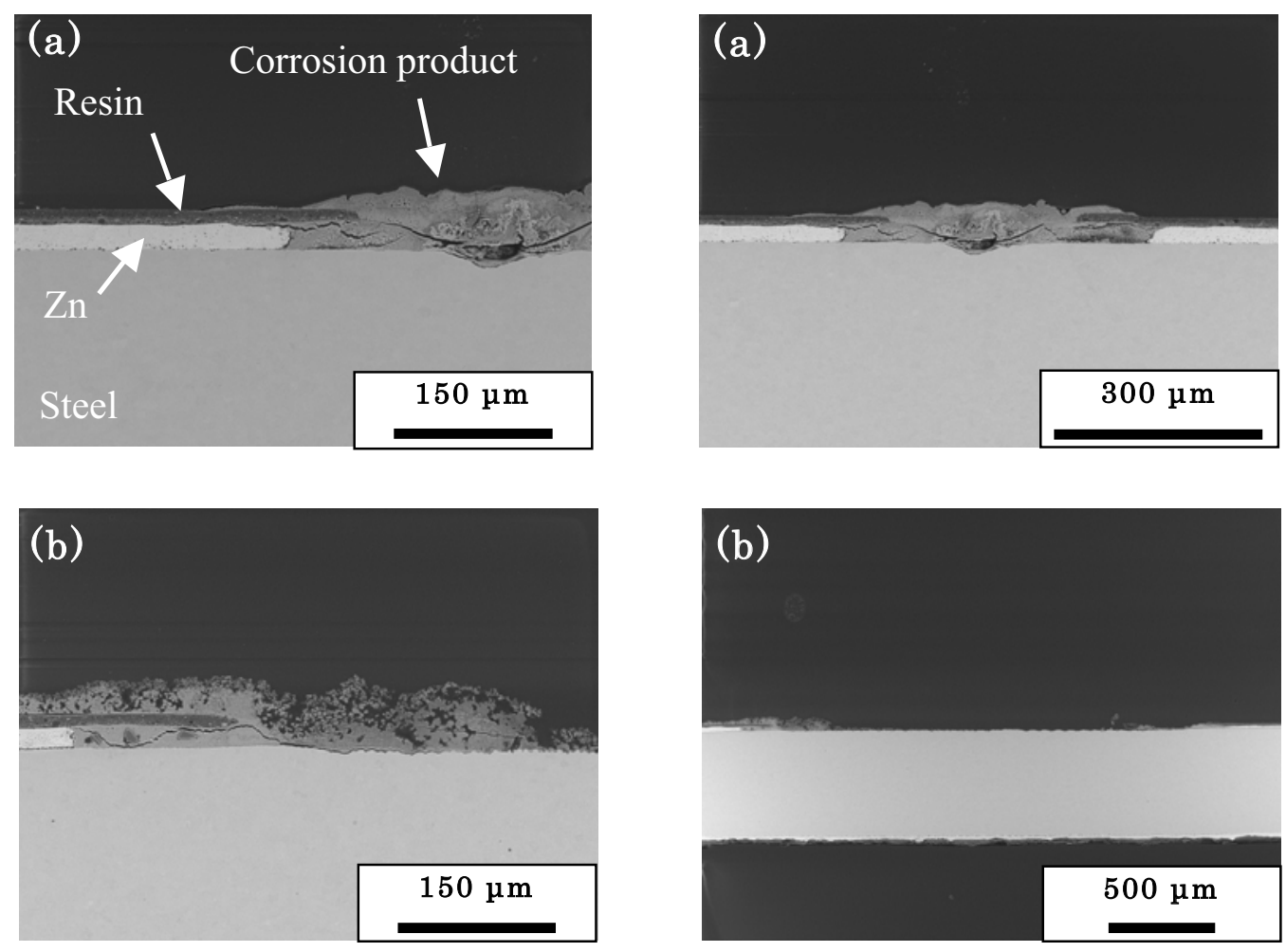

Figure 4. SEM images of cross-section of $\mathrm{Zn}-\mathrm{CR}\left(\mathrm{S}_{\mathrm{r}}=\right.$ (a) 0.7 , (b) 6.0) after wet/dry cycle corrosion test. Right row is overall images, and left row magnified images.

covered by corrosion products. Because of difference of cathodic reaction rate, amount of formed corrosion products on $\mathrm{S}_{\mathrm{r}}=6.0$ specimen is larger than that of $\mathrm{S}_{\mathrm{r}}=0.7$ specimen. From these images, corrosion of zinc was started at the outer rim of formed model cutedge, and progressed into the whole area of zinc coating under pre-painted area. The distance between paint and steel substrate is not changed by formation of corrosion products. This result suggests that some potion of the formed zinc related corrosion product might be squeezed out of the painted area. If the volume of squeezed out or corrosion product was sufficient to cover model cut-edge surface, steel substrate does not corrode itself to form red corrosion rust.

Figure 5 shows optical surface images of $\mathrm{Zn}-\mathrm{CF}$ specimens, $\mathrm{S}_{\mathrm{r}}=0.7$ and 6.0 , after 7 cycles of wet/dry corrosion test. There are zinc oxide related white corrosion products at formed model cut-edge. The red rust is also observed at center area of $\mathrm{S}_{\mathrm{r}}=6.0$ specimen surface, where white corrosion products are not covered. The amount of corrosion products in both $\mathrm{S}_{\mathrm{r}}=0.7$ and $6.0 \mathrm{Zn}-\mathrm{CF}$ specimens are larger than that of $\mathrm{Zn}-\mathrm{CR}$ specimens, and the color of red rust on $\mathrm{S}_{\mathrm{r}}=6.0$ is more clear. These results suggest that chromate inhibits corrosion of both zinc coating and steel substrate.

Figure 6 shows SEM images of cross-section of Zn-CF after wet-dry cycle corrosion test, $\mathrm{S}_{\mathrm{r}}=$ (a) 0.7, (b) 6.0. Left row is magnified images, and right row is overall images. The cross sectional images are almost same as shown in Fig. 5. Therefore corrosion mechanism or progress mechanism of under the pre-paint may not change by presence of chromate ions. 
(a) $\mathrm{S}_{\mathrm{r}}=0.7$

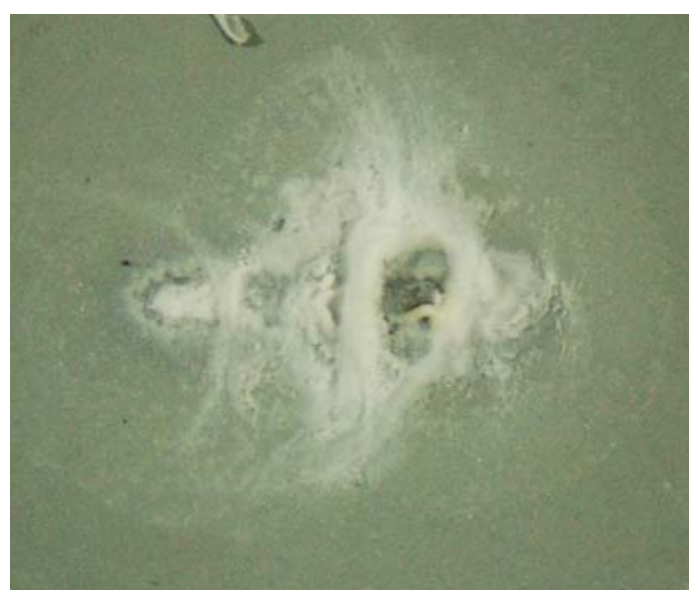

(b) $\mathrm{S}_{\mathrm{r}}=6.0$

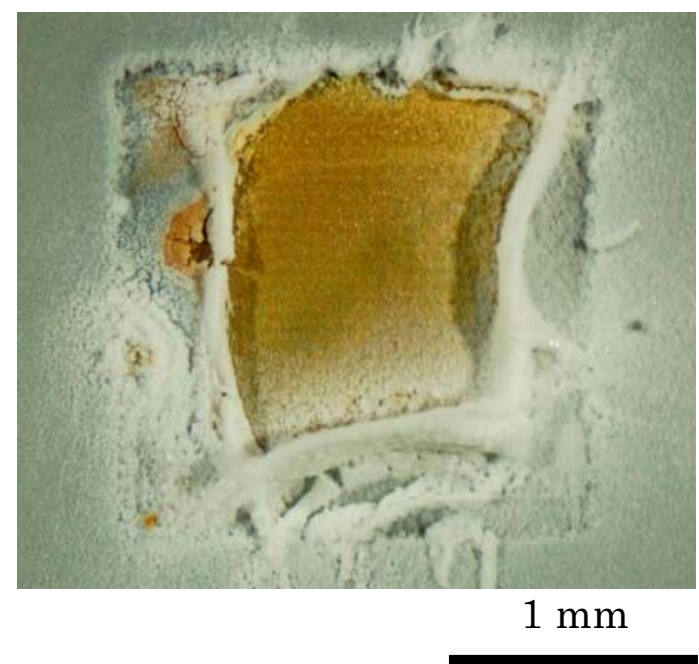

Figure 5. Optical surface images of Zn-CF specimens, $S_{\mathrm{r}}=0.7$ and 6.0, after 7 cycles of wet/dry corrosion test.

\section{Corrosion behavior of GL-CR and GL-CF}

Figure 7 shows optical surface images of GL-CR specimens, $S_{\mathrm{r}}=0.7$ and 6.0, after 7 cycles of wet/dry corrosion test. The surface images are very different from these of $\mathrm{Zn}$ $\mathrm{CR}$ and $\mathrm{Zn}-\mathrm{CF}$. White corrosion products covered almost all of the area of formed model
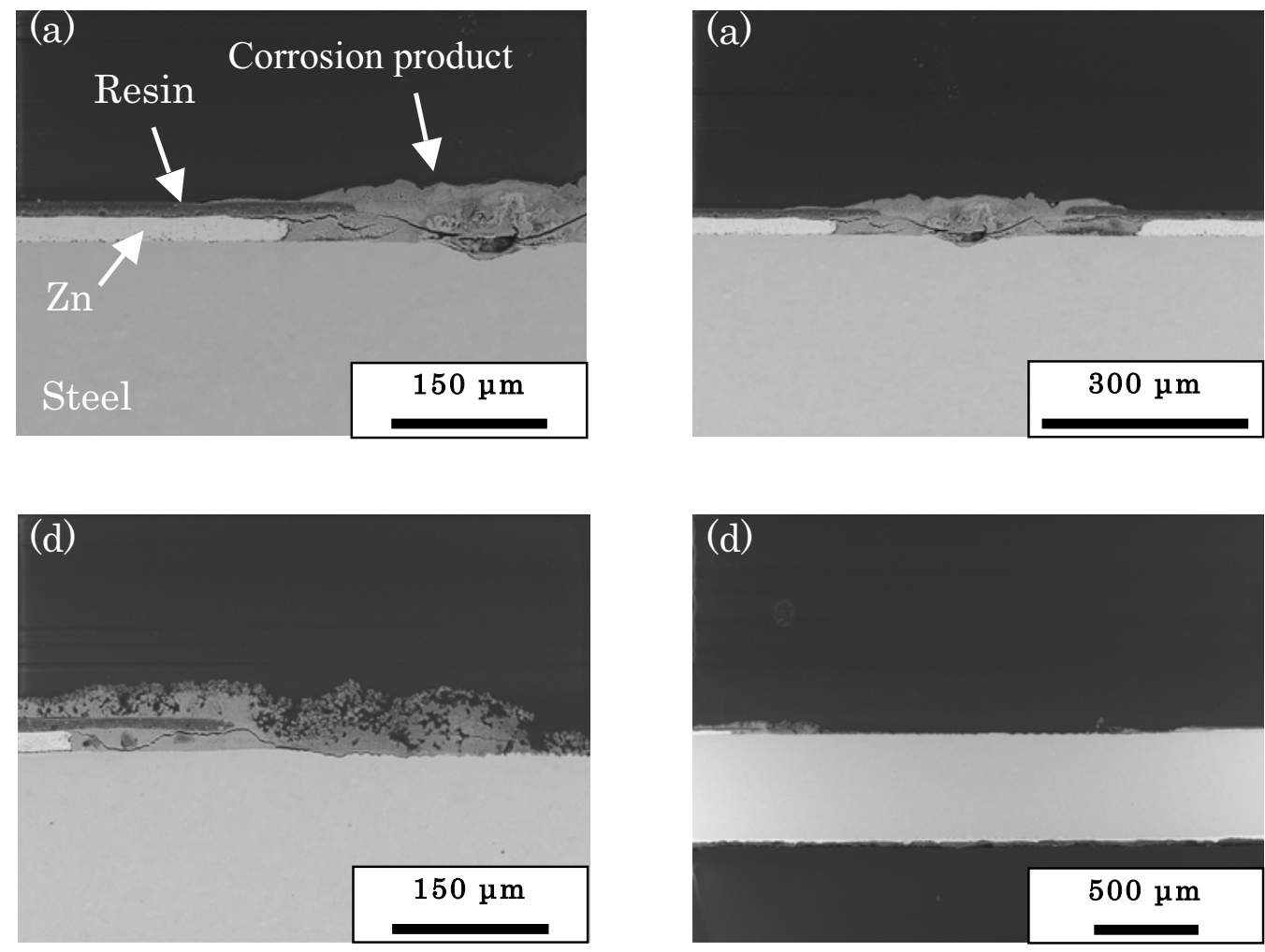

Figure 6. SEM images of cross-section of Zn-CF after wet/dry cycle corrosion test, $\mathrm{S}_{\mathrm{r}}$ $=(a) 0.7$, (b) 6.0. Left row is magnified images, and right row is overall images. 
(a) $\mathrm{S}_{\mathrm{r}}=0.7$

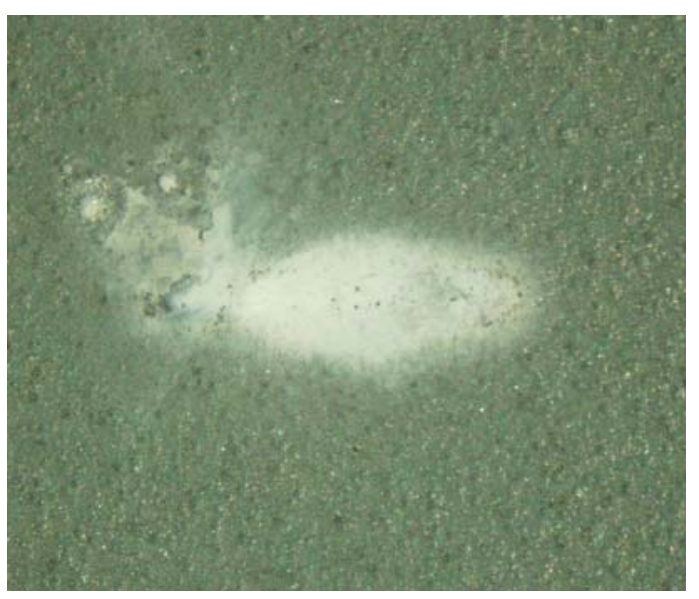

(b) $\mathrm{S}_{\mathrm{r}}=6.0$



Figure 7. Optical surface images of GL-CR specimens, $S_{\mathrm{r}}=0.7$ and 6.0 , after 7 cycles of wet/dry corrosion test.

cut-edge in both $\mathrm{S}_{\mathrm{r}}$. It may be because of steel surface also covered with white corrosion products, only few red rust can be seen, and some part of steel surface of $S_{r}=6.0$ specimen still remained bright. If the $S_{\mathrm{r}}$ is same, the total amount of corrosion product of GL-CR specimen looks smaller than that of Zn-CR specimen.

Figure 8 shows SEM images of cross-section of GL-CR after wet/dry cycle corrosion test, $\mathrm{S}_{\mathrm{r}}=$ (a) 0.7, (b) 1.4. Left row is magnified images, and right row is overall images. The zinc rich part of coating preferentially dissolved under the painting and aluminum rich part still remains even near the formed model cut-edge. Because of corrosion growth mechanism under the paint, corroded front of zinc-55 mass\% aluminum coating under the paint is longer than that of zinc coating and the paint of corroded area is pealed off from the coating (Fig. 7 (b)). The corrosion product has many pores in the side. The effect of aluminum on structure of corrosion products is not clear but dissolution of aluminum in the coating during wet/dry corrosion test may change solution $\mathrm{pH}$ or may induce hydrogen evolution.

Figure 9 shows optical surface images of GL-CF specimens, $\mathrm{S}_{\mathrm{r}}=0.7$ and 6.0, after 7 cycles of wet/dry corrosion test. The overall image is almost the same as Fig. 7, however, area of red rust on $\mathrm{S}_{\mathrm{r}}=6.0$ GL-CF specimen is larger than that of GL-CR specimen. These results suggest that chromate inhibits corrosion of both zinc- 55 mass $\%$ aluminum coating and steel substrate. The morphology of white corrosion products becomes rough on both $\mathrm{S}_{\mathrm{r}}$ specimens.

Figure 10 shows SEM images of cross-section of GL-CF after wet-dry cycle corrosion test, $\mathrm{S}_{\mathrm{r}}=$ (a) 0.7, (b) 1.4. Left row is magnified images, and right row is overall images. The cross sectional images are almost same as in Fig. 8, The zinc rich part of coating preferentially dissolved under the painting and aluminum rich part still remains even at near the formed model cut-edge. This result suggests that corrosion mechanism does not change with chromate ions. However, exfoliation length of paint on GL-CF specimens in Fig. 10 (b) is longer than that on GL-CR specimen. This may be corrosion inhibition property of chromate ions. 

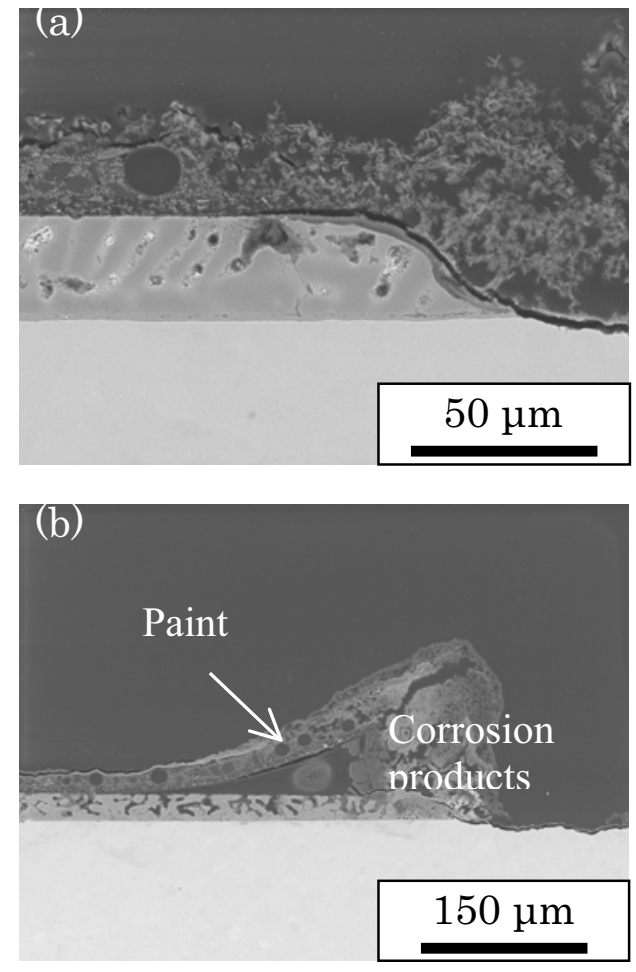
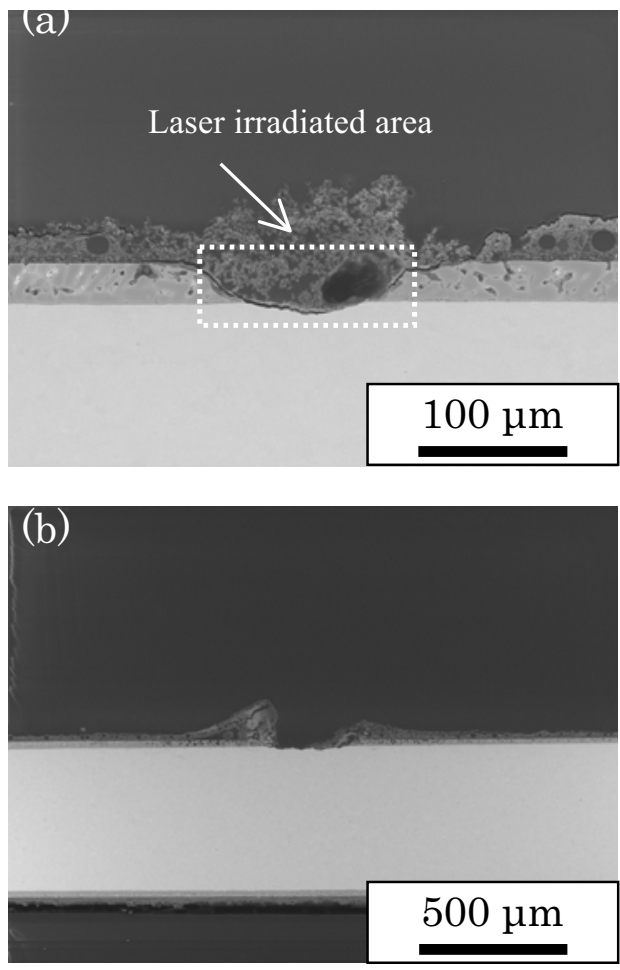

Figure 8. SEM images of cross-section of GL-CR after wet/dry cycle corrosion test, $\mathrm{S}_{\mathrm{r}}=$ (a) 0.7, (b) 1.4. Left row is magnified images, and right row is overall images.

(a) $\mathrm{S}_{\mathrm{r}}=0.7$

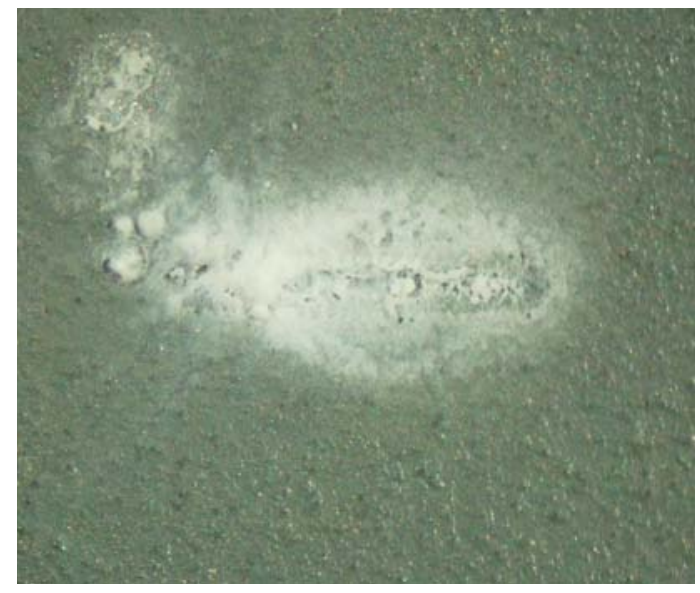

(b) $\mathrm{S}_{\mathrm{r}}=1.4$

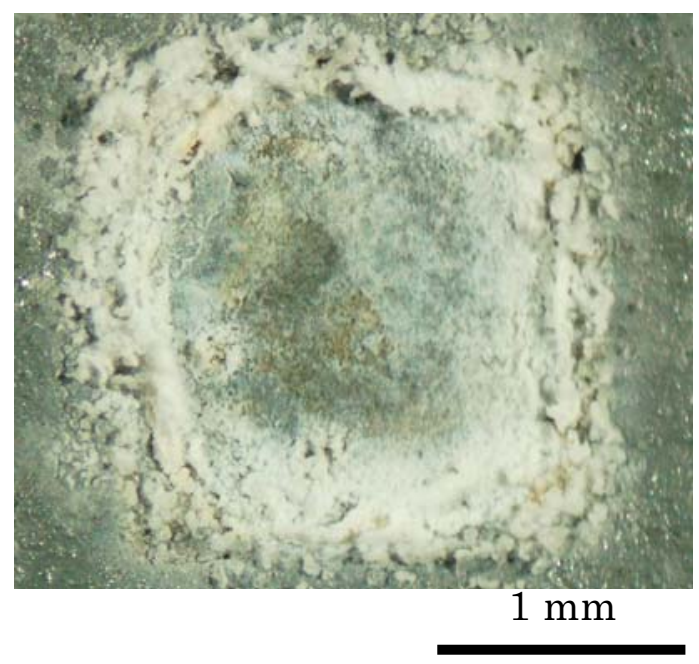

Figure 9. Optical surface images of GL-CF specimens, $S_{\mathrm{r}}=0.7$ and 6.0, after 7 cycles of wet/dry corrosion test.

The corrosion behavior of Zn-CF and GL-CF specimens suggests that cut-edge corrosion of chromate free pre-paint coated steels becomes more important for life prediction or long service time of the products. 

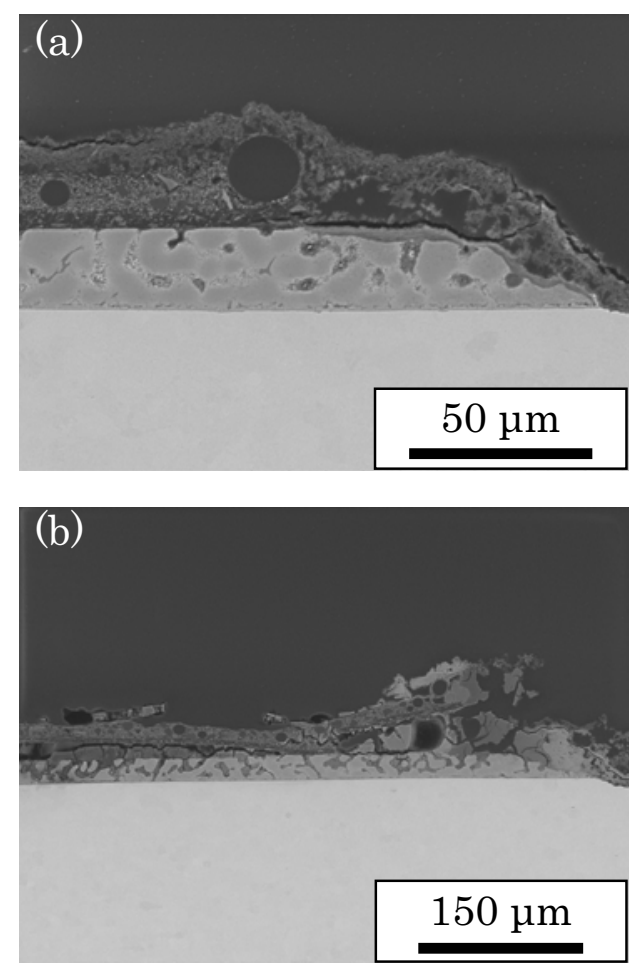
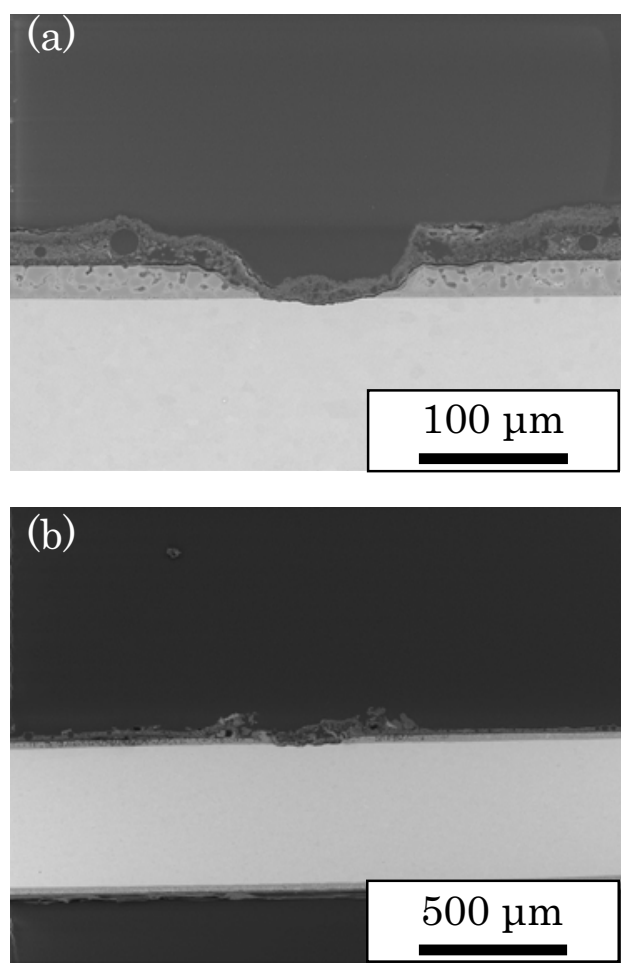

Figure 10. SEM images of cross-section of GL-CF after wet/dry cycle corrosion test, $\mathrm{S}_{\mathrm{r}}=$ (a) 0.7, (b) 1.4. Left row is magnified images, and right row is overall images.

\section{Conclusions}

The laser fabrication technique was applied to form model cut-edge on pre-painted coated steel. Following conclusions may be drawn.

1) In high $S_{r}$ of zinc specimens, red rust is observed on steel substrate at model cut edge, because zinc corrosion products inhibit sacrificial reaction of zinc. In both coating, chromate inhibits corrosion of model cut edge.

2) In the case of painted zinc coated steel, dissolution of coated layer starts at the cut edge and penetrates laterally.

3) In the case of painted zinc-55 mass $\%$ aluminum coated steel, zinc rich phase preferentially dissolved. The preferential zinc rich layer dissolution and corrosion products formation cause paint peel off of the zinc-alloy coating.

\section{Acknowledgments}

This study was carried out under the research project of "Research Report for Cut Edge Corrosion Mechanism and Life Predictions of Pre Painted Steel Sheets for Residential Use", The Iron and Steel Institute of Japan.

\section{References}

1. The Iron and Steel Institute of Japan, Research Report for Fundamentals of 
Corrosion Protection and Evaluation Methods on Zinc Alloy Coated Steels, Tokyo (2005).

2. X. G. Zhang, Corrosion and Elctro-chemistry of Zinc, Plenum Press, New York (1996).

3. H. E. Townsend and J. G. Zoccola, Material Paformance, 18, 13 (1979).

4. H. Shindo, K. Nishimura and K. Kato, Proc. of Galvatech98, 433 (1998).

5. S. Fujita, M. Yoshida, T. Odajima, T. Kanemaru and Y. Shindo, Tetsu to Hagane, 81, 54 (1995).

6. G. A. El-Mahdy, A. Nishikata and T. Tsuru, Corrs. Sci., 42, 183 (2000)

7. R. Lindstrom, J. E. Svensson and L. G. Jahnsson, J. Electrochem. Soc., 147, 1751 (2000).

8. M.Sakairi, Y. Uchida and H. Takahashi, ISIJ Int., 46, 1218 (2006).

9. M. Sakairi, Y. Uchida and H. Takahashi, Corros. Sci., 49, 2362 (2007) .

10. The Iron and Steel Institute of Japan, Research Report for Cut-Edge Corrosion Mechanism and Life Predictions of Pre Painted Steel Sheets for Residential Use, Tokyo (2009).

11. Y. Akiyama, T. Kikuchi, M. Ueda, M. Iida, M. Sakairi and H. Takahashi, Electrochim. Acta, 51, 4834 (2006).

12. T. Kikuchi, Y. Akiyama, M. Ueda, M. Sakairi and H. Takahashi, Electrochim. Acta, 52, 4480 (2007).

13. M. Sakairi, M. Yamada, T. Kikuchi and H. Takahashi, Electrochim. Acta, 52, 6268 (2007).

14. M. Sakairi, A. Kageyama and T. Kikuchi, Proc. of APGalva 2009, (2009).

15. T. Ohtsuka and Y. Abe, Proc. of GALVATEC'07, 648 (2007). 